\title{
PHYTOCHEMICAL MANAGEMENT OF DIABETIC COMPLICATIONS, EXPERIMENTAL EVIDENCES
}

\section{REKHA BISHT*}

Department of Pharmacology, Indore Institute of Pharmacy, Indore, Madhya Pradesh, India. Email: rekha.al03@gmail.com

Received: 4 June 2019, Revised and Accepted: 30 July 2019

\begin{abstract}
It is progressively obvious that not only is a cure for the current worldwide diabetes epidemic required but also for its major complications, affecting both small and large blood vessels. These complications occur in the majority of individuals with both Type- 1 and Type- 2 diabetes. Incidence and pervasiveness of diabetes mellitus are rapid becoming high in middle- and low-income countries where about $80 \%$ of people living in those countries depend on traditional medicines. Innumerable and diverse reports abound in the literature on studies conducted to investigate the ameliorative effects of medicinal plants on various pathophysiological complications of diabetes mellitus. Traditional medicines derived from medicinal plants are used by about $60 \%$ of the world's population. Although there are various perspectives to reduce the ill effects of diabetes and its secondary complications, herbal formulations are preferred due to lesser side effects and low cost. The present review emphasizes on medicinal plants that could be beneficial for the treatment of diabetes-induced macrovascular and microvascular complications.
\end{abstract}

Keywords: Diabetic complications, Diabetes, Type-1 diabetes, Type-2 diabetes, Macrovascular complication, Microvascular complication.

(C) 2019 The Authors. Published by Innovare Academic Sciences Pvt Ltd. This is an open access article under the CC BY license (http://creativecommons. org/licenses/by/4. 0/) DOI: http://dx.doi.org/10.22159/ajpcr.2019.v12i9.34442

\section{INTRODUCTION}

Diabetes mellitus is a group of chronic metabolic conditions, characterized by hyperglycemia arising from impaired insulin utilization coupled with the body's inability to indemnify with increased insulin production or resistance to insulin action, or both $[1,2]$. There are two major forms of diabetes, Type-1, and Type-2, although diabetes may also express during pregnancy (gestational diabetes) and under other conditions including drug or chemical toxicity, genetic disorders, endocrinopathies, insulin-receptor disorders, and in association with the pancreatic exocrine disease [3]. Type-1 diabetes mellitus is characterized by loss of insulin-producing beta cells of islets of Langerhans in the pancreas, thereby results in a deficiency of insulin. Type 1 diabetes in children is termed as juvenile diabetes. Insulin resistance or reduced insulin sensitivity combined with reduced insulin secretion is the major cause of Type- 2 diabetes [4]. The prevalence of diabetes mellitus has augmented exponentially over the past three decades, with a resultant increase in morbidity and mortality, mainly due to its complications. Increasing childhood obesity rates and the rising diagnosis of Type- 2 among children and young adults have become an increasingly dreadful health crisis, which will result in a large number of people having and managing diabetes and its complications for most of their lives [1]

Diabetic complications account for increased morbidity, impairment, and mortality and represent a warning for the economies of all countries, especially the developing ones [5]. It is increasingly evident that not only is a cure for the current worldwide diabetes epidemic required butalso for its major complications, affecting both small and large blood vessels [3]. The main microvascular complications are diabetic nephropathy, neuropathy, and retinopathy induced by chronic hyperglycemia through several mechanisms such as the production of advanced glycation end products (AGEs), the creation of a proinflammatory microenvironment, and the induction of oxidative stress [6]. Atherosclerosis is the most common macrovascular complication of diabetes mellitus. These complications occur in the majority of individuals with both Type- 1 and Type- 2 diabetes [3]. Research studies revealed that diabetic has 25 times the incidence of blindness as the nondiabetic, 17 times the incidence of kidney disease, 4 times the incidence of peripheral vascular disease, twice the incidence of coronary artery disease and stroke, and an almost universal incidence of neuropathy [7].
Despite significant progress in the management of diabetes mellitus, with insulin therapy, oral hypoglycemic agents, restricted diet, exercise, the search for indigenous antidiabetic agent still continues, as a large number of diabetic cases treated with traditional medicine in the form of plant extract have been reported to give exceptionally good results [7]. The World Health Organization also recommended and encouraged the use of herbal medicine, especially in countries where access to the conventional treatment of diabetes is not adequate [8]. Large numbers of medicinal plants are being looked up for the treatment of diabetes and its complications [9]. The present review highlights the research studies of medicinal plants exhibiting significant pharmacological effects on various diabetic macrovascular and microvascular complications.

\section{GLYCYRRHIZA GLABRA (LICORICE; F: LEGUMINOSAE)}

G. glabra L. is widely cultivated in the Mediterranean region and Southwest Asia [10]. Roots of G. glabra are used for its expectorant, diuretic, laxative, sedative, antipyretic, antimicrobial, hepatoprotective, antioxidant, antiulcer, and antiadhesive properties [11]. The protective action of G. glabra in diabetic (streptozotocin (STZ)-induced) nephropathy has been reported. Licorice extract alleviated blood glucose levels restored renal function and attenuated body-weight loss, modulated the adverse effect of diabetes on renal malondialdehyde (MDA), glutathione (GSH), superoxide dismutase, and catalase (CAT) activity. Absence of focal segmental glomerulosclerosis, tubular damage also revealed the therapeutic potential of licorice in diabetic nephropathy [12].

\section{CROTON LOBATUS (RUSHFOIL/CROTON; F: EUPHORBIACEAE)}

C. lobatus is an erect, annual, herbaceous plant, often harvested for local use as food and medicine. An investigation of the modulatory role of the methanol extract of $\mathrm{C}$. lobatus leaf on alloxan-induced diabetes and associated cardiovascular complications revealed reduced arteriogenic risk factors, improved antioxidant status, and improvement in observable pathological lesions associated with experimental diabetes in rats [13].

\section{CAMELLIA SINENSIS (GREEN TEA AND BLACK TEA EXTRACT; F: THEACEAE}

Green tea is manufactured from the leaves of the plant $C$. sinensis. Tea is consumed in different parts of the world as green, black, or oolong 
tea [14]. The hepatoprotective property of green tea extract has been reported in STZ-induced diabetic rats. Liver MDA content, serum levels of alanine aminotransferase, aspartate aminotransferase, alkaline phosphatase, bilirubin, serum albumin level and GSH, superoxide dismutase (SOD), CAT, and GSH-Px contents of the liver were significantly improved in extract-treated animals. Black and green tea has also been reported to exhibit beneficial effects on the risks of metabolic syndrome and cardiovascular diseases in diabetic animals [15].

\section{TRIGONELLA FOENUM-GRAECUM (FENUGREEK, F: LEGUMINOSAE)}

Species of Trigonella are widely distributed throughout the world. It is found on the continents of Asia (India and China), parts of Europe, Africa, Australia, and North and South America [16]. Treatment of diabetic rats with aqueous extract of seeds of $T$. foenum-graecum demonstrated the significant protection against functional and morphologic injuries in the kidneys [17]. The therapeutic potential of T. foenum-graecum on diabetic nephropathy has also been reported by Sayed. Significant reduction of high levels of glucose, urea, creatinine, sodium, potassium, and IL- 6 in serum and levels of MDA, and IL- 6 in the kidney homogenate by fenugreek was reported [18].

\section{ICHNOCARPUS FRUTESCENS (SARIVAA/KALIDUDH) F: APOCYNACEAE}

I. frutescens is a climbing plant, typically found in village surroundings and hedges. Roots are used as a demulcent, alterative, tonic, and diuretic, diaphoretic and are used as a substitute for Indian Sarsaparilla [19]. Significant reduction in urinary albumin and protein, effective protection against aldose reductase activity and protein damage concluded the possible therapeutic potential of a polyphenolic extract of I. frutescens in diabetic nephropathy [20].

\section{GYMNEMA MONTANUM (F: ASCLEPIADACEAE)}

G. montanum Hook is an endemic and endangered plant species found mainly in Western Ghats, India. G. montanum has been reported to show a significant effect on diabetes and associated complications. Plant extract significantly normalized the elevated blood glucose, renal markers (including urea, creatinine, and uric acid), and lipid peroxidation markers (thiobarbituric reactive substances and hydroperoxides), and increased antioxidant levels (antioxidant enzymes superoxide dismutase, CAT, GSH peroxidase, and GSH-Stransferase activities) in the diabetic kidney [21].

\section{PIMPINELLA TIRUPATIENSIS (KONDAKOTHIMERA, F: APIACEAE)}

P. tirupatiensis is a rare and endemic medicinal plant and restricted to the Seshachalam hills of the Eastern Ghats, India [22]. It is commonly used for anti-tumorigenic, antimicrobial, purgative, hypoglycemic, abortifacient, and analgesic, antiseptic, antipyretic, and anti-inflammatory [23]. The significant effect of aqueous extract of P. tirupatiensis tuberous root in the reversal of oxidative stress-induced cardiac dysfunction in diabetes mellitus has been reported. Xanthine oxidase activity, uric acid, and MDA contents were significantly elevated, and the contents of GSH and ascorbic acid were significantly diminished in diabetic rats [24].

\section{CANNABIS SATIVA L (HEMP, F: CANNABACEAE)}

C. sativa is grown specifically for the industrial uses for its derived products. It is used to prepare a variety of commercial items, including food and animal feed [25]. The antinociceptive effect of a controlled cannabis extract in attenuating diabetic neuropathic pain has been explored. The significant effect of cannabis extract on mechanical allodynia and physiological thermal pain perception without affecting hyperglycemia was observed. Restoration of the nerve growth factor content in the sciatic nerve of diabetic rats also highlighted the beneficial effects of cannabis extract treatment in attenuating diabetic neuropathic pain, possibly through a strong antioxidant activity and a specific action on nerve growth factor [26].

\section{EMBLICA OFFICINALIS (AMLA; F: EUPHORBIACEAE)}

E. officinalis is native to India, Sri Lanka, Malaysia, and China [27]. A combination of Insulin with E. officinalis extract not only attenuated the diabetic condition but also reversed neuropathic pain through modulation of oxidative-nitrosative stress in diabetic rats [28]

\section{STEVIA REBAUDIANA BERTONI (CANDY LEAF; F: ASTERACEAE)}

Stevia is a plant native to South America that has been used as a sweetener for hundreds of years [29]. Stevia is used in liver disease, stomachache, gastric hyperacidity, and as a mild agent stimulating the nervous system [30]. Treatment of STZ-induced diabetic animals with stevia leaves showed improved glucose tolerance and insulin sensitivity and alleviated glomerular filtration rate in the stevia leaves and extracted polyphenol fed groups. The study suggested a significant role of stevia leaves in improving diabetes-induced kidney damage [31].

\section{ALLIUM SATIVUM L. (GARLIC; F: ASTERACEAE)}

A. sativum is an important spice consumed globally and is bestowed with immense medicinal benefits [32]. Significant effects of A. sativum L. on diabetic nephropathy and oxidative stress have been reported. Fresh garlic homogenate can ameliorate STZ-induced diabetic nephropathy possibly through participation in the inhibition of oxidative damage to kidney and/or increased the kidney nitric oxide bioavailability [33].

\section{VITIS VINIFERA (GRAPES; F: VITACEAE)}

Grape seed proanthocyanidin extract (GSPE) is a natural product comprising a mixture of biologically active polyphenolic flavonoids. GSPE has remarkable properties against free radicals and oxidative stress [34]. A significant effect of GSPE was observed against diabetesinduced neuropathy. GSPE significantly increased the motor nerve conductive velocity, mechanical hyperalgesia and SOD and reduced the AGEs and tissue MDA of diabetic rats [35].

\section{CLEOME VISCOSA LINN. (WILD OR DOG MUSTARD; F: CAPPARIDACEAE)}

It is an annual, sticky herb found as a common weed all over the plains of India and throughout the tropics of the world. The whole plant and its parts are widely used in traditional and folkloric systems of medicine. The neuroprotective effect of ethanolic extract of $C$. viscosa (EECV) against STZ-induced diabetic neuropathy in Wistar rats has been observed. Chronic treatments with EECV for 4 weeks attenuated the level of nociceptive threshold significantly and dose-dependently [36].

\section{SYZYGIUM AROMATICUM (CLOVE; F: MYRTACEAE)}

S. aromaticum is a medium size tree (8-12 $\mathrm{m}$ ) native from the Maluku islands in East Indonesia [37]. The effect of eugenol from clove oil on diabetic vascular and nerve function in STZ-induced diabetic rats has been reported. Reduced sciatic nerve endoneurial blood flow and gastric fundus maximum nitrergic nerve-mediated by diabetes were corrected by $200 \mathrm{mg} / \mathrm{kg}$ eugenol treatment. For renal artery rings, eugenol corrected maximum endothelium-dependent relaxation to acetylcholine with improvements in both nitric oxide and endothelium-derived hyperpolarizing factor-mediated vasorelaxation components [38].

\section{CARUM CARVI (CARAWAY; F: APIACEAE)}

C. carvi is an annual and biennial economical one, widely used in food products due to its pleasant flavor and preservative properties. It is also used for its medicinal properties as a remedy to cure indigestion, pneumonia, and as a carminative, appetizer, and galactagogue in different traditional systems of medicine [39]. A study suggests that the high dose of $C$. carvi aqueous seed extract $(60 \mathrm{mg} / \mathrm{kg})$ showed renoprotection against STZ-induced diabetic nephropathy in rats [40].

\section{ACACIA NILOTICA (BABUL; F: MIMOSACEAE)}

A. nilotica, widely grown in Pakistan, is considered to be antispasmodic, and antidysenteric. Pods and tender leaves are given to treat diarrhea 
and are also considered very useful in folk medicine to treat diabetes mellitus [41]. Possible therapeutic potential of $A$. nilotica in diabetesinduced nephrotoxicity (150 and $300 \mathrm{mg} / \mathrm{kg}$ body weight, aqueous methanolic extract) has been observed. In addition to hypoglycemic activity, it restores the normal histopathological architecture of the kidney and showed a significant ameliorative effect on the glomerular size and damaged area [42].

\section{NIGELLA SATIVA (BLACK SEED; F: RANUNCULACEAE)}

$N$. sativa is very popular worldwide in various traditional systems of medicine such as Unani Tibb, Ayurveda, and Siddha. Seeds and oil have a long history of folklore usage in various systems of medicines and food [43]. The hepatoprotective effect of $N$. sativa in diabetic animals has been reported. $N$. sativa significantly escalated MDA concentrations, increased the lowered GSH and ceruloplasmin concentrations, and prevented lipid-peroxidation-induced liver damage in diabetic rabbits [44]

\section{AZADIRACHTA INDICA (NEEM, F: MELIACEAE)}

Neem has been widely used in Chinese, Ayurvedic, and Unani medicines worldwide, especially in the Indian subcontinent in the treatment and prevention of various diseases [45]. Treatment of diabetic rats with water extract of fresh leaves of A. indica resulted in reversed retinopathy. Furthermore, A. indica resulted in a significant fall in blood glucose and improvement in serum total, low-density lipoprotein (LDL), and highdensity lipoprotein cholesterol, and triacylglycerol [46].

\section{OLEA EUROPAEA L. (OLIVE; F: OLEACEAE)}

O. europaea L., the only species of the genus Olea, is used as food. It is widely found in the Mediterranean region [47]. An investigation of olive leaf extract on in vitro and in vivo models of diabetic pain neuropathy reports inhibition of high glucose-induced neural damage and suppresses diabetes-induced thermal hyperalgesia. The results suggest the therapeutic potential of olive leaf extract in the attenuation of diabetic neuropathic pain [48].

\section{FICUS RACEMOSA (INDIAN FIG TREE/GULAR; F: MORACEAE)}

F. racemosa is a popular medicinal plant in India, which has long been used in Ayurveda, for various diseases/disorders including diabetes, liver disorders, diarrhea, and inflammatory conditions [49]. Treatment with $F$. racemosa showed protection in the multiple pathways of diabetic neuropathy with neurodegeneration by improving blood glucose, hemoglobin A1c, biochemical, and behavioral parameters, which suggest the protective role of $F$. racemosa in the reversal of deep neural network [50].

\section{MORUS RUBRA (RED MULBERRY FRUIT; F: MORACEAE)}

M. rubra is native to eastern and central North America. It is used in food items such as beverages, breads, and cakes, dumplings and preserves and also a remedy for dysentery, laxative, and emetic. The anti-atherosclerotic effect of aqueous leaves extract of M. rubra in STZinduced diabetic rats fed with atherosclerotic diet has been reported. Endothelial dysfunction parameters (sVCAM-1, fibrinogen, total NO levels, and oxidized LDL), apolipoprotein (A) and apolipoprotein (B) were significantly $(\mathrm{p}<0.001)$ reversed to near normal, following treatment with the extract [51].

\section{CASSIA AURICULATA L. (AVARTAKI; F: CAESALPINIACEAE)}

The C. auriculata herb has been immensely used in traditional Ayurvedic medicine for treating diabetes, rheumatism, asthma, and skin diseases [52]. The anti-atherosclerotic potential of aqueous extract of C. auriculata L. leaves was reported in STZ-induced diabetic rats. In addition, a significant reversal in altered serum lipid profile and apolipoprotein B along with the reversal of fatty change toward normal on histopathological examination of heart myocardium was observed in extract-treated diabetic rats [53].

\section{MORUS INDICA L. (BLACK MULBERRY; F: MORACEAE)}

M. indica is known for its nutritional qualities, flavor, and for its traditional use in natural medicine as it has a high content of active therapeutic compounds [54]. Andallu B reported that dried leaf powder of mulberry ( $M$. indica L.) controlled hyperglycemia, glycosuria, albuminuria, and the retarded onset of retinopathy [55].

\section{EUGENIA JAMBOLANA (JAVA PLUM/JAMUN FRUIT; F: MYRTACEAE)}

E. jambolana, a berry fruit, grows abundantly in tropical regions of South Asia and South America and is used in traditional medicines such as Ayurveda [56]. Anti-atherosclerotic effect of active principle; $\alpha$-hydroxy succinamic acid isolated from aqueous fruit pulp extract of E. jambolana in STZ-induced diabetic animals has been reported (at a dose of 10,15 , and $20 \mathrm{mg} / \mathrm{kg}$ ). $\alpha$-hydroxy succinamic acid exhibited significant $(\mathrm{p}<0.001)$ improvement in blood glucose, serum lipid profile, apolipoproteins, and endothelial dysfunction parameters [57].

\section{ANNONA MURICATA (SOURSOP/GRAVIOLA; F: ANNONACEAE)}

A. muricata is widely distributed in tropical and subtropical regions of the world. The fruits of $A$. muricata are widely used to prepare syrups, candies, beverages, ice creams, and shakes [58]. Treatment of STZ-induced diabetic rats with $A$. muricata seed extract revealed antiatherogenic effect as the histological assessment of the aorta showed widely dilated, moderately thickened wall in extract-treated groups [59].

\section{ALOE BARBADENSIS (ALOE VERA; F: LILIACEAE)}

A. vera grows mainly in the dry regions of Africa, Asia, Europe, and America. In India, it is found in Rajasthan, Andhra Pradesh, Gujarat, Maharashtra, and Tamil Nadu [60]. Saberi investigated the effect of $A$. vera gel in the thickness of the retinal layers, and the study suggests that in the group treated with $A$. vera, the thickness of the retina and its layers retained their normal histological structures [61].

\section{POLYGONUM CUSPIDATUM (KNOTWEED; F: POLYGONACEAE)}

P. cuspidatum has been used clinically for the treatment of constipation, gallstones, hepatitis, and inflammation [62]. An investigation on the effect of the ethanol extract of the root of $P$. cuspidatum (PCE) on retinal inflammation in diabetic retinopathy suggests that PCE has a preventative effect against diabetes-induced vascular permeability by inhibiting high mobility group box-1-RAGE-NF-_B activation in diabetic retinas [63].

\section{AEGLE MARMELOS (BAEL/SIRPHAL; F: RUTACEAE)}

A. marmelos (L.) Corr., popularly known as bael tree [64] is native to Northern India but widely found throughout the Indian peninsula and in Ceylon, Burma, Bangladesh, Thailand, and Indo-China [65]. A. marmelos is reported to exhibit a significant ameliorative effect on early changes induced in the kidneys by alloxan. Furthermore, a significant reduction was observed in fasting blood sugar, total cholesterol, blood urea, creatinine, and renal thiobarbituric acid reactive substances; however, levels of renal reduced GSH and CAT were increased in extract treated diabetic animals [66].

\section{MORUS ALBA (MULBERY, F: MORACEAE)}

M. alba has been widely cultivated to feed silkworms. Its leaves and roots have been used in traditional medicine as a cathartic, analgesic, diuretic, antitussive, sedative, hypotensive, and antiphlogistic, and for the treatment of edema [67]. Possible ameliorative effect of crude water extract of $M$. alba leaves on retinopathy of rat pups maternally subjected to diabetes and/or Al intoxication was reported. Marked amelioration was observed in the retina of pups maternally received $M$. alba extract [68].

\section{LANTANA CAMARA (LANATA, F: VERBENACEAE)}

L. camara, a native plant from tropical America, is considered one of the most harmful invasive species worldwide [69]. Dose- 
dependent augmentation in wound contraction rate and hastening of epithelialization period by the extract of $L$. camara was exhibited in diabetic animals [70].

\section{OCIMUM SANCTUM (TULSI; F: LAMIACEAE)}

O. sanctum $\mathrm{L}$. is native throughout the world tropics and widespread as a cultivated plant. It is cultivated for medicinal and religious purposes and its essential oil [71]. About $50 \%$ ethanol extract of 0 . sanctum promote wound healing by enhancing connective tissue formation and antioxidants status with a decrease in blood glucose level, free radicals, and myeloperoxidase in STZ (45 mg/kg)-induced diabetic rats [72].

\section{CONCLUSION}

In folk/traditional systems of medicines, different plants have been used individually or in formulations for the treatment of diabetes and its complications. However, the major drawback in the popularization and commercialization of herbal medicines has been the scarcity of authoritative clinical data related to the effectiveness of improving diabetic complications. It is foremost to explore the active component and their molecular interaction, which will assist to analyze therapeutic effectiveness of the product and also to standardize the product. Defined clinical studies coupled with state of analytical experiments for persuading the quality product are the need of the hour. It is important to explore the potential of this therapeutics for the management of diabetes and related complications. Thus, the present review highlights the potential of natural products for the treatment of diabetic complications such as neuropathy, nephropathy, retinopathy, and CVS diseases. Efforts are now being made to investigate the mechanism of action of active ingredients of these plants using model systems.

\section{AUTHOR'S CONTRIBUTION}

The author has contributed to writing and correction of the manuscript.

\section{CONFLICTS OF INTEREST}

The author declares that they have no conflicts of interest.

\section{REFERENCES}

1. Deshpande AD, Harris-Hayes M, Schootman M. Epidemiology of diabetes and diabetes-related complications. Phys Ther 2008;88:1254-64.

2. Jose D, Aleykutty NA, Jyoti H. Effect of combination of two plant extracts on diabetes mellitus. Int J Pharm Pharm Sci 2018;10:49-52.

3. Forbes JM, Cooper ME. Mechanisms of diabetic complications. Physiol Rev 2013;93:137-88

4. Subramania K, Pathakb S, Hosseinkhani H. Recent trends in diabetes treatment using nanotechnology. Dig J Nanomater Biostruct 2012; 7:85-95

5. Naslafkih A, Sestier F. Diabetes mellitus related morbidity, risk of hospitalization and disability. J Insur Med 2003;35:102-13.

6. Nguyen DV, Shaw LC, Grant MB. Inflammation in the pathogenesis of microvascular complications in diabetes. Front Endocrinol (Lausanne) 2012;3:170

7. Henry WL Jr. The complications of diabetes mellitus. J Natl Med Assoc 1987;79:677-80.

8. Gogoi N, Bhuyan B. In vivo anti-diabetic activity evaluation of the bark of Cascabela thevetia L. In streptozotocin induced diabetic rats. Int J Pharm Pharm Sci 2017;9:48-53.

9. Modak M, Dixit P, Londhe J, Ghaskadbi S, Devasagayam TP. Indian herbs and herbal drugs used for the treatment of diabetes. J Clin Biochem Nutr 2007;40:163-73.

10. Namazi N, Alizadeh M, Mirtaheri E, Farajnia S. The effect of dried Glycyrrhiza glabra L. extract on obesity management with regard to PPAR- $\gamma 2$ (Pro12Ala) gene polymorphism in obese subjects following an energy restricted diet. Adv Pharm Bull 2017;7:221-8

11. Raveendra KR, Jayachandra, Srinivasa V, Sushma KR, Allan JJ, Goudar KS, et al. An extract of Glycyrrhiza glabra (GutGard) alleviates symptoms of functional dyspepsia: A randomized, doubleblind, placebo-controlled study. Evid Based Complement Alternat Med 2012;2012:216970.
12. Kataya HH, Hamza AA, Ramadan GA, Khasawneh MA. Effect of licorice extract on the complications of diabetes nephropathy in rats. Drug Chem Toxicol 2011;34:101-8.

13. Fasola TR, Ukwenya B, Oyagbemi AA, Omobowale TO, Ajibade TO. Antidiabetic and antioxidant effects of Croton lobatus L. In alloxaninduced diabetic rats. J Intercult Ethnopharmacol 2016;5:364-71.

14. Chacko SM, Thambi PT, Kuttan R, Nishigaki I. Beneficial effects of green tea: A literature review. Chin Med 2010;5:13.

15. Ramadan G, El-Beih NM, Abd El-Ghffar EA. Modulatory effects of black v. Green tea aqueous extract on hyperglycaemia, hyperlipidaemia and liver dysfunction in diabetic and obese rat models. Br J Nutr 2009:102:1611-9.

16. Goyal S, Gupta N, Chatterjee S. Investigating therapeutic potential of Trigonella foenum-graecum L. As our defense mechanism against several human diseases. J Toxicol 2016;2016:1250387.

17. Xue W, Lei J, Li X, Zhang R. Trigonella foenum-graecum seed extract protects kidney function and morphology in diabetic rats via its antioxidant activity. Nutr Res 2011;31:555-62.

18. Sayed AA, Khalifa M, Abd el-Latif FF. Fenugreek attenuation of diabetic nephropathy in alloxan-diabetic rats: Attenuation of diabetic nephropathy in rats. J Physiol Biochem 2012;68:263-9.

19. Sini S, Malathy NS. Phytochemical characteristics of Ichnocarpus frutescens. (L) R.Br. Anc Sci Life 2006;25:71-5.

20. Kumarappan CT, Mandal SC. Polyphenolic extract of Ichnocarpus frutescens attenuates diabetic complications in streptozotocin-treated diabetic rats. Ren Fail 2008;30:307-22.

21. Ramkumar KM, Ponmanickam P, Velayuthaprabhu S, Archunan G, Rajaguru P. Protective effect of Gymnema montanum against renal damage in experimental diabetic rats. Food Chem Toxicol 2009;47:2516-21.

22. Ananthan R, Latha M, Ramkumar KM, Pari L, Baskar C, Bai VN, et al. Effect of Gymnema montanum leaves on serum and tissue lipids in alloxan diabetic rats. Exp Diabesity Res 2003;4:183-9.

23. Palani S, Raja S, Rajalingam D, Kumar RP, Kumar BS. Therapeutic Efficacy of Pimpinella tirupatiensis (Apiaceae) on acetaminophen induced hepatotoxicity and oxidative stress in male albino rats. Pharmacologyonline 2009;2:708-19.

24. Saddala RR, Thopireddy L, Ganapathi N, Kesireddy SR. Regulation of cardiac oxidative stress and lipid peroxidation in streptozotocin-induced diabetic rats treated with aqueous extract of Pimpinella tirupatiensis tuberous root. Exp Toxicol Pathol 2013;65:15-9.

25. Yang Y, Lewis MM, Bello AM, Wasilewski E, Clarke HA, Kotra LP, et al. Cannabis sativa (Hemp) seeds, $\Delta^{9}$-tetrahydrocannabinol, and potential overdose. Cannabis Cannabinoid Res 2017;2:274-81.

26. Comelli F, Bettoni I, Colleoni M, Giagnoni G, Costa B. Beneficial effects of a Cannabis sativa extract treatment on diabetes-induced neuropathy and oxidative stress. Phytother Res 2009;23:1678-84.

27. Lim DW, Kim JG, Kim YT. Analgesic effect of Indian gooseberry (Emblica officinalis fruit) extracts on postoperative and neuropathic pain in rats. Nutrients 2016;8:760.

28. Tiwari V, Kuhad A, Chopra K. Emblica officinalis corrects functional, biochemical and molecular deficits in experimental diabetic neuropathy by targeting the oxido-nitrosative stress mediated inflammatory cascade. Phytother Res 2011;25:1527-36.

29. Ashwell M. Stevia, nature's zero-calorie sustainable sweetener: A new player in the fight against obesity. Nutr Today 2015;50:129-34.

30. Marcinek K, Krejpcio Z. Stevia rebaudiana Bertoni: Health promoting properties and therapeutic applications. J Verbr Lebensm 2015;11:3-8.

31. Shivanna N, Naika M, Khanum F, Kaul VK. Antioxidant, anti-diabetic and renal protective properties of Stevia rebaudiana. J Diabetes Complications 2013;27:103-13.

32. Raghu R, Lu KH, Sheen LY. Recent research progress on garlic as a potential anticarcinogenic agent against major digestive cancers. J Tradit Complement Med 2012;2:192-201.

33. Mariee AD, Abd-Allah GM, El-Yamany MF. Renal oxidative stress and nitric oxide production in streptozotocin-induced diabetic nephropathy in rats: The possible modulatory effects of garlic (Allium sativum L.). Biotechnol Appl Biochem 2009;52:227-32.

34. Salahuddin A, Katary M. Effects of grape seed proanthocyanidin extract in attenuating diabetic complications in streptozotocin-induced diabetic rats. J Appl Pharm 2017;9:1-6.

35. Cui XP, Li BY, Gao HQ, Wei N, Wang WL, Lu M, et al. Effects of grape seed proanthocyanidin extracts on peripheral nerves in streptozocininduced diabetic rats. J Nutr Sci Vitaminol (Tokyo) 2008;54:321-8.

36. Rao BS, Reddy KE, Parveen K, Narendra BL, Shekhar SC, Mangala L, et al. Effects of Cleome viscosa on hyperalgesia, oxidative stress and lipid profile in STZ induced diabetic neuropathy in Wistar rats. Pak J Pharm Sci 2014;27:1137-45. 
37. Cortés-Rojas DF, de Souza CR, Oliveira WP. Clove (Syzygium aromaticum): A precious spice. Asian Pac J Trop Biomed 2014;4:90-6.

38. Nangle MR, Gibson TM, Cotter MA, Cameron NE. Effects of eugenol on nerve and vascular dysfunction in streptozotocin-diabetic rats. Planta Med 2006;72:494-500.

39. Mahboubi M. Caraway as important medicinal plants in management of diseases. Nat Prod Bioprospect 2019;9:1-11.

40. Sadiq S, Nagi AH, Shahzad M, Zia A. The reno-protective effect of aqueous extract of Carum carvi (black zeera) seeds in streptozotocin induced diabetic nephropathy in rodents. Saudi J Kidney Dis Transpl 2010;21:1058-65.

41. Gilani AH, Shaheen F, Zaman M, Janbaz KH, Shah BH, Akhtar MS, et al. Studies on antihypertensive and antispasmodic activities of methanol extract of Acacia nilotica pods. Phytother Res 1999;13:665-9.

42. Omara EA, Nada SA, Farrag AR, Sharaf WM, El-Toumy SA. Therapeutic effect of acacia nilotica pods extract on streptozotocin induced diabetic nephropathy in rat. Phytomedicine 2012;19:1059-67.

43. Ahmad A, Husain A, Mujeeb M, Khan SA, Najmi AK, Siddique NA, et al. A review on therapeutic potential of Nigella sativa: A miracle herb. Asian Pac J Trop Biomed 2013;3:337-52.

44. Meral I, Yener Z, Kahraman T, Mert N. Effect of Nigella sativa on glucose concentration, lipid peroxidation, anti-oxidant defence system and liver damage in experimentally-induced diabetic rabbits. J Vet Med A Physiol Pathol Clin Med 2001;48:593-9.

45. Alzohairy MA. Therapeutics role of Azadirachta indica (Neem) and their active constituents in diseases prevention and treatment. Evid Based Complement Alternat Med 2016;2016:11.

46. Hussain HE. Reversal of diabetic retinopathy in streptozotocin induced diabetic rats using traditional Indian anti-diabetic plant, Azadirachta indica (L.). Indian J Clin Biochem 2002;17:115-23.

47. Hashmi MA, Khan A, Hanif M, Farooq U, Perveen S. Traditional uses, phytochemistry, and pharmacology of Olea europaea (Olive). Evid Based Complement Alternat Med 2015;2015:541591.

48. Kaeidi A, Esmaeili-Mahani S, Sheibani V, Abbasnejad M, Rasoulian B, Hajializadeh Z, et al. Olive (Olea europaea L.) leaf extract attenuates early diabetic neuropathic pain through prevention of high glucoseinduced apoptosis: In vitro and in vivo studies. J Ethnopharmacol 2011;136:188-96.

49. Ahmed F, Urooj A. Pharmacognostical studies on Ficus racemosa stem bark. Pharmacogn J 2011;3:19-24.

50. Solanki ND, Bhavsar SK. An evaluation of the protective role of Ficus racemosa Linn. In streptozotocin-induced diabetic neuropathy with neurodegeneration. Indian J Pharmacol 2015;47:610-5

51. Sharma SB, Tanwar RS, Rini AC, Singh UR, Gupta S, Shukla SK, et al. Protective effect of Morus rubra L. Leaf extract on dietinduced atherosclerosis in diabetic rats. Indian $\mathrm{J}$ Biochem Biophys 2010;47:26-31.

52. Rajendran V, Krishnegowda A, Nachiappan V. Antihyperlipidemic activity of Cassia auriculata flower extract in oleic acid induced hyperlipidemia in Saccharomyces cerevisiae. J Food Sci Technol 2017;54:2965-72.

53. Gupta S, Sharma SB, Singh UR, Bansal SK. Salutary effect of Cassia auriculata L. Leaves on hyperglycemia-induced atherosclerotic environment in streptozotocin rats. Cardiovasc Toxicol 2011;11:308-15.

54. Niratkers CR, Preeti, Malti. Antimicrobial activity of leaf extract of Morus indica (Mulberry) from Chhattisgarh. Asian J Plant Sci Res
2015;5:28-31

55. Andallu B, Varadacharyulu NCh. Control of hyperglycemia and retardation of cataract by mulberry (Morus indica L.) leaves in streptozotocin diabetic rats. Indian J Exp Biol 2002;40:791-5.

56. Donepudi AC, Aleksunes LM, Driscoll MV, Seeram NP, Slitt AL. The traditional ayurvedic medicine, Eugenia jambolana (Jamun fruit), decreases liver inflammation, injury and fibrosis during cholestasis. Liver Int 2012;32:560-73.

57. Tanwar RS, Sharma SB, Singh UR, Prabhu KM. Antiatherosclerotic potential of active principle isolated from Eugenia jambolana in streptozotocin-induced diabetic rats. Evid Based Complement Alternat Med 2011;2011:127641

58. Moghadamtousi SZ, Fadaeinasab M, Nikzad S, Mohan G, Ali HM, Kadir HA, et al. Annona muricata (Annonaceae): A review of its traditional uses, isolated acetogenins and biological activities. Int J Mol Sci 2015; 16:15625-58

59. Agbai EO, Njoku CJ, Nwanegwo CO, Nwafor A. Effect of aqueous extract of Annona muricata seed on atherogenicity in streptozotocininduced diabetic rats. Afr J Pharm Pharmacol 2015;9:745-55.

60. Surjushe A, Vasani R, Saple DG. Aloe vera: A short review. Indian J Dermatol 2008;53:163-6.

61. Saberi M, Gholami S. An investigation on the effects of the Aloe vera extract on the thickness of the retina in male diabetic rats. Iran J Vet Res 2012;13:296-302.

62. Kim YS, Lee YM, Kim JH, Kim JS. Polygonum cuspidatum inhibits pancreatic lipase activity and adipogenesis via attenuation of lipid accumulation. BMC Complement Altern Med 2013;13:282.

63. Sohn E, Kim J, Kim CS, Lee YM, Kim JS. Extract of Polygonum cuspidatum attenuates diabetic retinopathy by inhibiting the highmobility group box-1 (HMGB1) signaling pathway in streptozotocininduced diabetic rats. Nutrients 2016;8:140.

64. Bisht R, Bhattacharaya S. Some medicinal plants of Uttarakhand (India) with antimicrobial activity: A review. Pharmacologyonline 2011;2:428-439.

65. Rahman S, Parvin R. Therapeutic potential of Aegle marmelos (L.) an overview. Asian Pac J Trop Dis 2014;4:71-7.

66. Bhatti R, Sharma R, Singh J, Singh A, Ishar MP. Effect of Aegle marmelos (L.) Correa on alloxan induced early stage diabetic nephropathy in rats. Indian J Exp Biol 2013;51:464-9.

67. Yadav AV, Kawale LA, Nade VS. Effect of Morus alba L. (mulberry) leaves on anxiety in mice. Indian J Pharmacol 2008;40:32-6.

68. El-Sayyed H, Badawy G, Elnabi SH, Elaimy I, Al Shehari E. Ameliorative effect of Morus alba leaves extract against developmental retinopathy in pups of diabetic and aluminum intoxicated pregnant albino rats. Asian Pac J Trop Biomed 2015;5:300-9.

69. Goncalves E, Herrera I, Duarte M, Bustamante RO, Lampo M, Velásquez G, et al. Global invasion of Lantana camara: Has the climatic niche been conserved across continents? PLoS One 2014;9:e111468.

70. Mekala S, Kumar NM, Das L, Shetty N, Amuthan A, Vulli V, et al. Evaluation of wound healing activity of ethanolic extract of Lantana camara in streptozotocin induced diabetic rats. Int J Pharm Pharm Sci 2014;6:631-3.

71. Pattanayak P, Behera P, Das D, Panda SK. Ocimum sanctum Linn. A reservoir plant for therapeutic applications: An overview. Pharmacogn Rev 2010;4:95-105.

72. Gautam MK, Goel RK. Wound healing effect of Ocimum sanctum leaves extract in diabetic rats. Int J Pharmacol Pharm Sci 2013;7:538-42. 